\title{
CLINICAL CASES
}

Dent. Med. Probl. 2016, 53, 1, 142-146

DOI: $10.17219 / \mathrm{dmp} / 60347$ (c) Copyright by Wroclaw Medical University and Polish Dental Society ISSN 1644-387X

Tomasz Krzysztof JaChewiCZ ${ }^{\text {A-D }}$, Beata NyrkA ${ }^{\text {A, D, E }}$

\section{Mucocele of the Glands of Blandin-Nuhn - Case Report}

\section{Torbiel gruczołu Blandin-Nuhna - opis przypadku}

Department of Oral Surgery, Lublin Medical University, Lublin, Poland

A - research concept and design; $\mathbf{B}$ - collection and/or assembly of data; C - data analysis and interpretation;

$\mathbf{D}$ - writing the article; $\mathbf{E}$ - critical revision of the article; $\mathbf{F}$ - final approval of article

\begin{abstract}
A mucocele is a retention cyst in the oral mucosa of small salivary glands. The changes occur predominantly within the lower lip, but sometimes in other locations where there are small salivary glands - on the tongue, floor of the mouth, buccal mucosa, upper lip and palate.

This paper presents the rare case of a patient of the Department of Oral Surgery at the Medical University in Lublin, with a Blandin-Nuhn gland cyst, located on the ventral side of the tongue. A patient diagnostic puncture was performed, which confirmed the clinical diagnosis. The cyst was removed using a classical surgical technique described in the article. The paper discusses the causes, predisposing factors and the mechanisms of their formation. We describe two types of cysts which have different locations for stopping the secretions. We present the histology of the retention and extravasation types. We describe the types of salivary glands present on the tongue and the anatomy of the Blandin-Nuhn gland. The authors present the possible locations of retention cysts in the ventral tongue, and present methods of conservative and surgical treatment of Blandin-Nuhn mucoceles. The authors discuss the differential diagnosis and clinical manifestations (Dent. Med. Probl. 2016, 53, 1, 142-146).
\end{abstract}

Key words: minor salivary glands, tongue, mucocele, Blandin-Nuhn mucocele.

Słowa kluczowe: małe gruczoły ślinowe, język, torbiel zastoinowa, torbiel Blandin-Nuhna.

An oral mucocele is a mucous retention cyst. It may occur in the mucous membrane of the oral cavity, in various areas [1]. It most often occurs on the inner surface of the lower lip of young people, $75 \%$ of all lesions according to some authors, less often in other locations with small salivary glands - on the tongue, bottom of the oral cavity, cheek, upper lip or palate $[2,3]$.

The frequency of the occurrence of mucous retention cysts in the oral cavity is low and is below $1 \%$ in most studies [4].

There are two etiological factors of the occurrence of oral mucoceles: injury and a closure of the ducts of the salivary glands. Thus, mucous cysts occur as a result of extravasations or a retention of mucus [5].

Lesions can be divided into two types as far as the place of retention of the gland's secretion is concerned. Mucous extravasation cysts occur when saliva is retained in the connective tissues. The type more often observed in young people, in the lower lip, is related to the injury etiology. At such a young age, the presence of mixed dentition, the shape of the incisors, bad habits, i.e. socalled para-functions, and delicate oral cavity tissues vulnerable to damage, favor mechanical injuries of the tissues of the salivary glands. Injuries also occur in older patients, especially with loss of teeth. One result of recurring micro-traumas can be a disruption of salivary ducts or damage of the parenchyma of salivary glands. Mucous retention cysts develop following the soaking of saliva into the submucosa and its surroundings through the layer of fibroblasts [5].

A histopathological image presents granulation tissue and connective tissue compressed by 
the collected secretion with inflammatory changes. The occurrence of fibrous tissue most probably has a substantial importance for the limitation of mucus proliferation $[4,5]$.

In contrast to cysts occurring as a result of extravasation, retention mucoceles appear more often in older patients, are most common for the population over 40 and rarely occur in the area of the lip [2]. They form due to a stenosis of the salivary duct caused by inflammatory states, the presence of lime scale or mucus plugs. A continuous flow of the secretion causes an increase of tension in the area of the duct stenosis, which leads to a broadening of the duct and formation of a cyst [5].

According to histopathological images, there is sated fluid surrounded by a capsule with a single-layer epithelium, formed of cylindrical cells of the duct or cubic cells coming from a run of the point of the connection of a gland and a glandular duct $[4,5]$.

There are three groups of glands within a human tongue: Weber's glands alongside the surface, Ebner's glands around the lingual papillae and the glands of Blandin-Nuhn on the front part of the tongue [6].

A gland of Blandin-Nuhn is composed of numerous, small, mixed mucus and serous glands, located on both sides of the central line, forming a shape of a horseshoe on the front part of the tongue, which are covered by a thin mucous membrane. The gland is about $8 \mathrm{~mm}$ wide and 12-24 mm thick. It has from 5 to 8 ducts, which medially come from plicae fimbriatae on both sides of the fraenulum of the tongue $[2,7,8]$.

Mucoceles from glands of Blandin-Nuhn are rarely observed. According to Harrison, in a group of 400 oral mucoceles, only 9 were in the tongue, constituting 2.3\% [9]. According to Saza [10], mucoceles located on the front side of the tongue were stated at $9.6 \%$ of 385 cases. In the work by Jinbu et al. [5], cysts from the glands of Blandin-Nuhn constitute $9.9 \%$ of all oral mucoceles. In the case of young patients, salivary cysts of the front part of the tongue are more frequent than in older persons. According to Nico et al. [11], in a group of 104 patients, 50\% were aged below 20 and 34.6\% were aged below 15. As stated by de Camargo Moraes et al. [6], a substantial group of patients was of children's age, $10-19$ ( 22 cases $-46.9 \%$ ), and only 2 patients (4\%) were persons aged over 40 .

Mucoceles of the glands of Blandin-Nuhn can be located anywhere in the front area of the tongue. Jinbu et al. [5] noted that in 17 of 26 cases $(65 \%)$, the lesions were located in the area of the tongue tip and $9(34 \%)$ in the middle of the distance between the tip and root. Also, 19 cases
(73\%) were in the middle line and 7 cysts were observed laterally from the middle line. The research of de Camargo Moraes [6] covered a group of 312 cases or oral mucocele, only 48 of which (15.4\%) were located within tongue. In this group, 34 cases $(70.8 \%)$ occurred in the middle line, $2(4 \%)$ in the lateral part and 12 (25.2\%) between the tip and root.

In the diagnosis of salivary cysts, an essential thing is a clinical image, acknowledged by a histopathological diagnosis. A forming lesion has a rapid tip, is soft, fluid-filled, and shows periodic changes of size. An image of these lesions depends on the depth of the location in soft tissues and the level of keratosis of the mucosa. Cysts from the glands of Blandin-Nuhn laying on the surface are transparent, sky blue and have a semifluid consistency. More deeply located mucoceles are covered with a mucous membrane of normal color.

In the clinical diagnosis of mucous retention cysts from the glands of Blandin-Nuhn, it is helpful to use a fine-needle biopsy, which should show the presence of mucus. Glands of Blandin-Nuhn mucoceles mostly have a diameter of several millimeters, but occasionally can reach several centimeters. Larger lesions can disrupt speech, proper nutrition and occlusion. Those located on the back part of the tongue can additionally cause occlusions of the respiratory duct and obstruct breathing.

The symptoms of cysts from the glands of Blandin-Nuhn are characteristic for retention cysts. A typical factor is their location on the front part of the tongue. Such cysts should be differentiated from vascular lesions, pyogenic granuloma, squamous papilloma and polyps [2].

Modern protocols of treatment for BlandinNuhn pseudo-cysts include conservative and operational treatment. The selection of a treatment method depends on the location, size and patient's age. Conservative treatment covers laser ablation, cryosurgery, thermal coagulation, steroid injections with $0.05 \%$ clobetasol propionate or injection of $3 \%$ iodine into the cyst's interior [12, 13]. The advantages of this type of treatment include low invasiveness, less bleeding and fewer posttreatment complications. However, the frequency of relapses is high. Ren and Tian [14] stated that in the period of 3 years from a treatment using $3 \%$ iodine, they observed a relapse of cysts in $42.2 \%$ to $52.4 \%$ of cases.

In order to improve the visualization of the mucocele range, there is a possibility to inject thin silicone into the gland interior, preceded by mucus aspiration. Using this method is efficient and safe in the treatment of mucoceles in the front part of the tongue as cysts with very thin walls, laying on 
the surface under mucous membrane tend to easily fracture and can relapse if complete myomectomy is not undertaken [15].

Treatment using electro-surgery has numerous advantages, including minimal trauma rate, less bleeding, shorter time of the surgeon's work and smaller scars in soft tissues, which makes it recommended in cases of pediatric patients and patients not tolerating long surgeries [16].

Yeh [17] used cryosurgery for the removal of the mucocele in 36 cases. Cysts from the glands of Blandin-Nuhn were subjected to freezing in 4 consecutive cycles, once a week. At the surface of the lesions, after an application of liquid nitrogen, there were visible ice crystals formed due to the dehydration of cells, causing mechanical damage to the cyst wall. Treatment with cryosurgery does not leave scars, reduces swelling and pain, and does not require surgical suturing, which is often related to damage of the salivary ducts. According to the author, only 2 lesions (5.6\%) in the studied group relapsed [18].

An alternative method of surgical treatment of salivary gland cysts is micro-marsupialization and marsupialization. The former consists of implanting thick silk threads into a cyst wall at its largest protrusion, in order to form a micro-drainage for the retained mucus. The threads are removed after $7-10$ days and this is a sufficient period for closure of the mucocele. This method is recommended in cases of minor lesions in the group of pediatric patients. Larger cysts can be treated using marsupialization. An external wall is cut to allow the fluid to flow out to the oral cavity and the epithelium of the cyst wall is stitched to surrounding soft tissues in order to prevent relapses [12, 19].

Surgical treatment of cysts remains a basic therapeutic method [20]. Enucleation of the Blandin-Nuhn mucocele is performed at the front part of the tongue with a Y cut. A part of the gland is located in the depth of the tongue muscles in a small area. Due to the deep location, it is difficult to completely remove all the covered glands using traditional surgical treatments, which sometimes results in relapses after the first treatment. Working in a narrow treatment area can cause heavy bleeding due to damage to the lingual artery and damage to the hypoglossal nerve can cause swelling of the tongue, numbness and difficulty breathing [16].

\section{Case Report}

A 44-year-old patient reported to the Department of Oral Surgery of Lublin Medical University. In the history, he stated that he had been observing an evident protrusion on the front part of tongue for 2-3 weeks. In the course of a clinical examination, lesions were noted of $2-3 \mathrm{~cm}$ in diameter, with a smooth, soft surface, covered with a mucous membrane. Using palpation, a fluctuation symptom was felt. In order to diagnose and decompress, a diagnostic puncture was done, releasing a sticky, dense content of yellow color (Fig. 1). After 7 days, the patient returned for a follow up visit during which a cyst of the same size was diagnosed again (Fig. 2). At $2 \%$ infiltration and conduction anesthesia, a cyst of the salivary glands of Blandin-Nuhn was subject to exposure and enucleation using a classical treatment technique (Fig. 3). The wound was sutured with a simple interrupted stitch (Fig. 4). The removed lesion was sent for histopathological examination. The patient reported for follow up visits and the post-treatment period passed without complications. The stitches were removed after seven days. The histopathological examination confirmed the clinical diagnosis - salivary gland retention cyst.

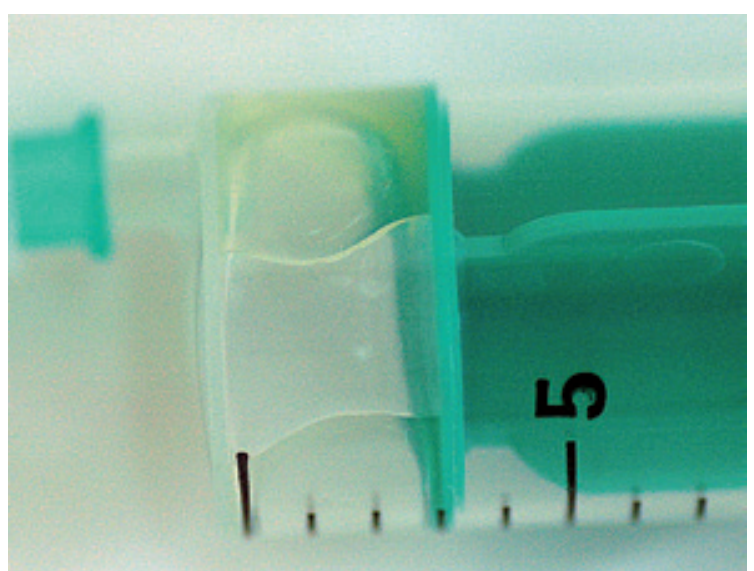

Fig. 1. Result of diagnostic puncture

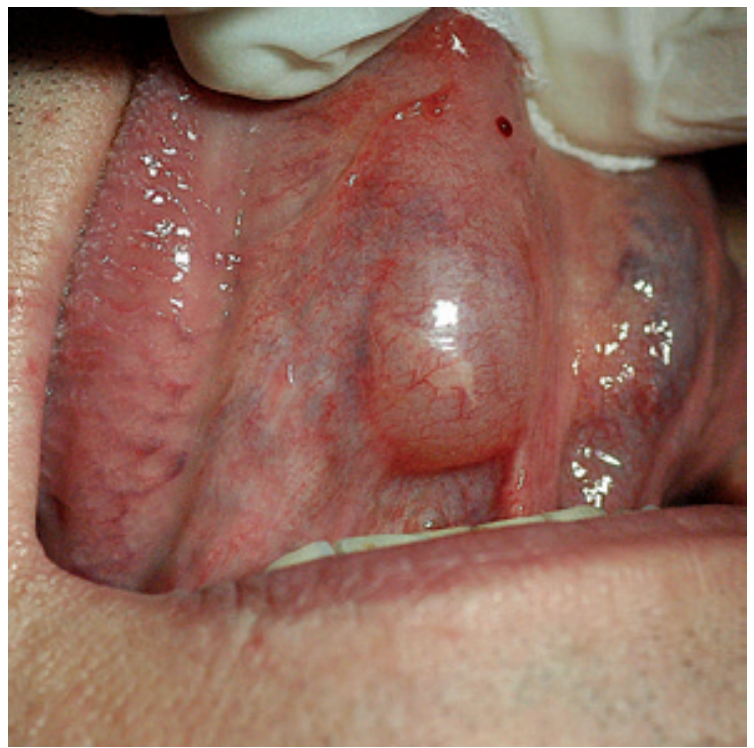

Fig. 2. Clinical picture of lesion before surgery 


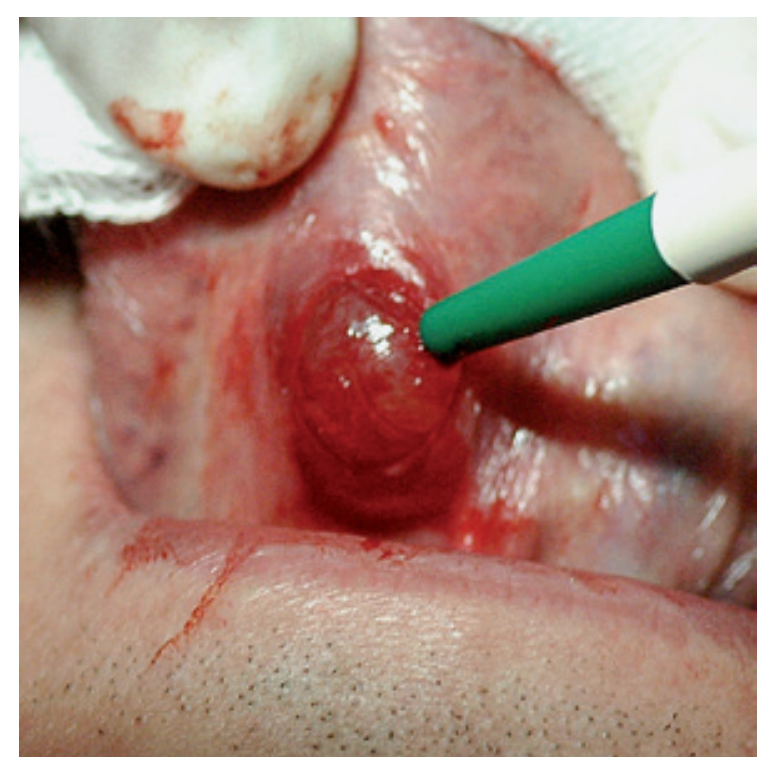

Fig. 3. Dissected mucocele

\section{Discussion}

A cyst of the glands of Blandin-Nuhn in the case of patients aged over 40 is rarely observed, more often occurring in children and young people. In the presented case, the study was characteristic of retention cysts [21]. The patient did not report pain, stating that he had noticed the lesion 2-3 weeks earlier. He reported obstructed swallowing and speech.

The clinical image was quite typical. The lesion was located on the front side of the tongue, in its middle part, laterally from the central line. Many authors suggest that it should be the tip itself. However, Jinbu et al. [5] and de Camargo Moraes et al. [6] notice the occurrence of cysts in various parts of the front side of the body of the tongue. The lesion's size of $2-3 \mathrm{~cm}$ is quite typical, however smaller ones of several $\mathrm{mm}$ are observed more often. During the palpation, a fluctuating syndrome was noted, related to movement of the cyst content caused by its pressure. This happens when a lesion is located on the sur-

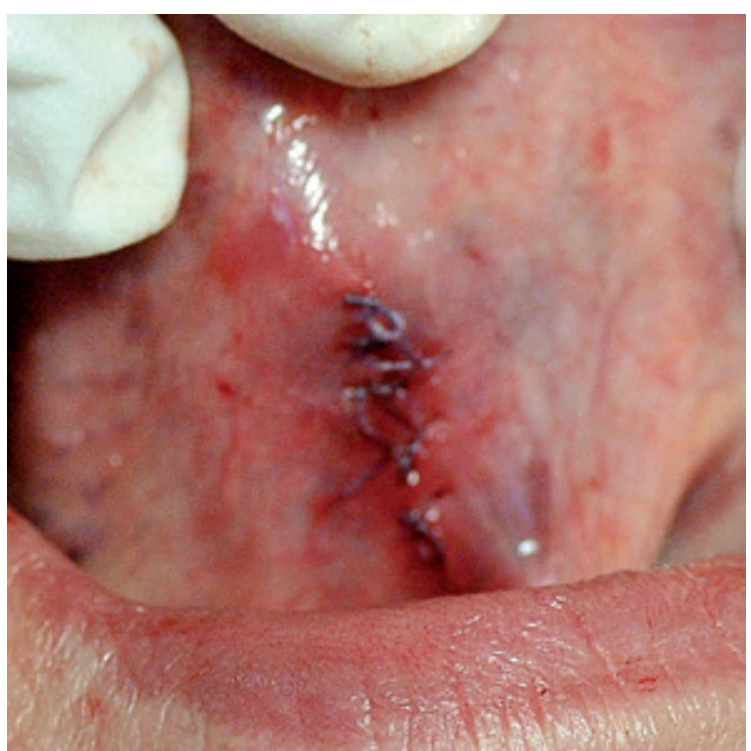

Fig. 4. State after sutures

face [22]. Despite such location in the described case, the cyst was covered with pink mucous membrane.

During the first visit, a diagnostic puncture was performed, releasing a characteristic sticky, yellow fluid. Despite decompression during another visit after 7 days, a cyst of similar size was observed again. It may happen that there are periodic changes of cyst size in cases when it breaks and secretion is accumulated again [22]. In practice, spontaneous healing of a lesion after its puncture or breaking is not observed.

The cyst was removed using a classical treatment method. Such decision was made due to the possibility of performing a precise exposure of the lesion, which enabled its complete enucleation. During treatment, it may happen that a cyst wall is broken in the initial phase of its exposure. According to the authors' experience, in such cases, it is better to change the procedure into marsupialization. In order to decrease the possibility of such a situation, it is possible to fill the cyst lumen with silicone before treatment [15].

\section{References}

[1] Andiran N., Sarikayalar F., Unal O.F., Baydar D.E., Ozaydin E.: Mucocele of the anterior lingual salivary glands: from extravasation to an alarming mass with a benign course. Int. J. Pediatr. Otorhinolaryngol. 2001, 61, 143-147.

[2] Adachi P., Soubhia A.M., Horikawa F.K., Shinohara E.H.: Mucocele of the glands of Blandin-Nuhn - clinical, pathological, and therapeutic aspects. Oral Maxillofac. Surg. 2011, 15, 11-13.

[3] Yamasoba T., Tayama N., Syoji M., Fukuta M.: Clinicostatistical study of lower lip mucoceles. Head \& Neck, 1990, 12, 316-320.

[4] Bednarz W., Orchel-Bednarz M.: Mucous cyst of salivary gland (Mucocele) - diagnostics and methodology of treatment - a case report. e-Dennico, 2009, 21, 64-73 [in Polish].

[5] Jinbu Y., Kusama M., Iтон H., Matsumoto K., Wang J., Noguchi T.: Mucocele of the glands of BlandinNuhn: a clinical and histopathologic analysis of 26 cases. Oral Surg. Oral Med. Oral Pathol. Oral Radiol. Endod. 2003, 95, 467-470. 
[6] de Camargo Moraes P., Bönecker M., Furuse C., Thomaz L.A., Teixeira R.G., de Araújo V.C.: Mucoceles of the gland of Blandin-Nuhn: histological and clinical findings. Clin. Oral Investig. 2009, 13, 351-353.

[7] Mandel L., Kaynar A.: Mucocele of the gland of Blandin-Nuhn. NY State Dent. J. 1992, 58, 40-41.

[8] Sugerman P.B., Savage N.W., Young W.G.: Mucocele of the anterior lingual salivary glands (glands of Blandin and Nuhn): report of 5 cases. Oral Surg. Oral Med. Oral Pathol. Oral Radiol. Endod. 2000, 90, 478-482.

[9] Harrison J.D.: Salivary mucoceles. Oral Surg. Oral Med. Oral Pathol. 1975, 39, 268-278.

[10] SAzA H.: Clinico-statistical study of salivary mucoceles. Jpn. J. Oral Maxillofac. Surg. 1982, 28, 1545-1550.

[11] Nico M.M., PARK J.H., Lourenço S.V.: Mucocele in pediatric patients analysis of 36 children. Pediatric Dermatol. 2008, 25, 308-311.

[12] Kumaresan R., Karthikeyan P., Mohammed F., Thapasum Fairozekhan A.: A novel technique for the management of a Blandin-Nuhn mucocele: a case report. Int. J. Clin. Pediatr. Dent. 2013, 6, 201-204.

[13] Sarada P., Reddy C.H., Ak P., Kurra S.: Solitary nodular lesion of tongue - a rare entity. J. Clin. Diag. Res. 2014, $8,256-258$.

[14] Ren Y.F., Tian R.X.: A discussion of the treatment of Blandin-Nuhn mucoceles. Chin. J. Misdiagnosis to Learn, 2009, 14, 3295-3296.

[15] Luiz A.C., Hiraki K.R., Lemos C.A., Hirota S.K., Migliari D.A.: Treatment of painful and recurrent oral mucoceles with a high-potency topical a corticosteroid: a case report. J. Oral. Maxillofac. Surg. 2008, 66, 1737-1739.

[16] Zhenpeng Z.: A clinical investigation of electrosurgical knife burning to treat Blandin-Nuhn mucoceles. Cancer Cell Res. 2014, 2, 42-46.

[17] YeH C.J.: Simple cryosurgical treatment for oral lesion. Int. J. Oral Maxillofac. Surg. 2000, 29, 211-216.

[18] Rezende K.M.: Cryosurgery as an effective alternative for treatment of oral lesion in children. Braz. Dent. J. 2014, $25,352-356$.

[19] Nindi M., Arun R.: Excision of mucocele: a surgical case report. Biol. Biomed. Rep. 2012, 2, 115-118.

[20] Mansur R., Świątkowski W., Jachewicz T.: Large radicular cyst of maxilla. A case report. Stomatol. 2015, 1-2, 16-19 [In Polish].

[21] Baurmash H.D.: Mucoceles and ranulas. J. Oral. Maxillofac. Surg. 2003, 61, 369-378.

[22] Guimarães M.S., Hebling J., Filho V.A., Santos L.L., Vita T.M., Costa C.A.: Extravasation mucocele involving the ventral surface of the tongue (glands of Blandin-Nuhn). Int. J. Paediatr. Dent. 2006, 16, 435-439.

\section{Address for correspondence:}

Tomasz Jachewicz

Goplan 47/1

20-828 Lublin

Poland

E-mail: jaho112@op.pl

Conflict of Interest: None declared

Received: 24.09 .2015

Revised: 1.10 .2015

Accepted: 25.10.2015 